\title{
Reproducibility of computed tomography angiography data analysis using semiautomated plaque quantification software: implications for the design of longitudinal studies
}

\author{
Stella-Lida Papadopoulou • Hector M. Garcia-Garcia • \\ Alexia Rossi • Chrysafios Girasis · Anoeshka S. Dharampal • \\ Pieter H. Kitslaar • Gabriel P. Krestin • Pim J. de Feyter
}

Received: 27 July 2012/Accepted: 29 November 2012/Published online: 7 December 2012

(C) Springer Science+Business Media Dordrecht 2012

\begin{abstract}
Reproducibility of the quantitative assessment of atherosclerosis by computed tomography coronary angiography (CTCA) is paramount for the design of longitudinal studies. The purpose of this study was to assess the inter- and intra-observer reproducibility using semiautomated CT plaque analysis software in symptomatic individuals. CTCA was performed in 10 symptomatic patients after percutaneous treatment of the culprit lesions and was repeated after 3 years. The plaque quantitative analysis was performed in untreated vessels with mild-tomoderate atherosclerosis and included geometrical and compositional characteristics using semiautomated CT plaque analysis software. A total of 945 matched crosssections from 21 segments were analyzed independently by a second reviewer to assess inter-observer variability; the first observer repeated all the analyses after 3 months to assess intra-observer variability. The observer variability was also compared to the absolute plaque changes detected over time. Agreement was evaluated by Bland-Altman analysis and concordance correlation coefficient. Inter-
\end{abstract}

S.-L. Papadopoulou $(\bowtie) \cdot$ H. M. Garcia-Garcia · A. Rossi ·

C. Girasis - A. S. Dharampal · P. J. de Feyter

Department of Cardiology, Erasmus University Medical Center,

Room Ca 207, PO Box 2040, 3000 CA Rotterdam,

The Netherlands

e-mail: elpa98@gmail.com; s.papadopoulou@erasmusmc.nl

S.-L. Papadopoulou · A. Rossi · A. S. Dharampal ·

G. P. Krestin - P. J. de Feyter

Department of Radiology, Erasmus University Medical Center,

PO Box 2040, 3000 CA Rotterdam, The Netherlands

P. H. Kitslaar

Division of Image Processing, Department of Radiology,

Leiden University Medical Center, Leiden, The Netherlands observer relative differences for lumen, vessel, plaque area and plaque burden were $1.2,0.6,2.2,1.6 \%$ respectively. Intra-observer relative differences for lumen, vessel, plaque area and plaque burden were $1.0,0.4,0.2,0.4 \%$ respectively. For the average plaque attenuation values the inter- and intra-observer variability was 5 and $2 \%$ respectively. For the $\%$ low-attenuation-plaque the interand intra-observer variability was 16 and $6 \%$ respectively. The absolute intra-observer variability for the plaque burden was $1.30 \pm 1.09 \%$, while the temporal plaque burden difference was $3.55 \pm 3.02 \%(p=0.001)$. The present study shows that the geometrical assessment of coronary atherosclerosis by CTCA is highly reproducible within and between observers using semiautomated quantification software and that serial plaque changes can be detected beyond observer variability. The compositional measurements are more variable between observers than geometrical measurements.

Keywords Agreement - Atherosclerosis .

Computed tomography angiography .

Plaque quantification · Reproducibility

\section{Introduction}

Coronary atherosclerosis is a worldwide disease with a burden of 17 million deaths annually [1]. In the past, quantitative coronary angiography (QCA) [2] and intravascular ultrasound (IVUS) have been used to study the extent of the disease [3] and monitor the progression/ regression of atherosclerosis. Nevertheless, both imaging techniques are invasive, expensive and not free of complications, thus unsuitable for routine serial assessment of atherosclerosis. 
Computed tomography coronary angiography (CTCA) has been introduced as a noninvasive technique for atherosclerotic plaque quantification in vivo. To date, there are several CTCA studies describing the extent, severity, distribution, and morphology of coronary atherosclerosis, including several longitudinal studies assessing plaque progression/regression by CTCA [4-11].

Reproducibility of measurements is crucial for the internal validity of longitudinal studies using CTCA; as previous serial studies using IVUS and CTCA have shown, the temporal changes in atherosclerotic plaque are small $[11,12]$. The use of semiautomated plaque analysis software which can produce accurate and reproducible quantitative measurements can facilitate the serial assessment of atherosclerosis by CTCA. However, only scarce data are available about the reproducibility of quantitative measurements for geometrical and compositional parameters of atherosclerotic plaque and a comparison with serial changes in plaque parameters is lacking.

Therefore, the aims of our study were the following: (1) to assess the inter-observer and intra-observer agreement of plaque geometrical measurements using semiautomated CTCA plaque analysis software; and as secondary objectives (2) to investigate the influence of the variability of the plaque contours position on the compositional measurements; and (3) to compare the observer variability with the serial changes in plaque burden and plaque area.

\section{Methods}

\section{Patient population}

In this exploratory study, the population comprised 10 randomly selected patients (21 segments and 945 crosssections) from a prospective cohort of symptomatic patients; this main cohort included 32 patients with acute coronary syndromes who underwent CTCA after percutaneous treatment of the culprit lesions and follow-up CTCA after 3 years to assess plaque temporal changes in the untreated vessels, as part of the PROSPECT MSCT substudy in our institution [11]. The institutional review board approved the study and all patients gave written informed consent.

\section{CTCA acquisition}

All patients received CT coronary angiography at baseline and 3 years follow-up which was performed using a 64-slice single source scanner (Sensation 64, Siemens Medical Solutions, Forchheim, Germany) and a 64-slice dual source CT scanner (Somatom Definition, Siemens Medical Solutions, Forchheim, Germany) respectively; the scanning protocol has been previously described in detail [11]. The patients received nitrates and $\beta$-blockers prior to the scan provided there were no contraindications. The CT angiographic scan parameters were: (1) for the single source CT scanner a gantry rotation time of $330 \mathrm{~ms}$; $32 \times 2$ slices per rotation; $0.6 \mathrm{~mm}$ detector collimation; spiral scan mode with a table feed of $3.8 \mathrm{~mm}$ per rotation; a tube voltage of $120 \mathrm{kV}$; and tube current of 900 effective mAs. A bolus of $100 \mathrm{~mL}$ of contrast material $(400 \mathrm{mgI} /$ $\mathrm{mL}$; Iomeron, Bracco, Milan, Italy) was injected intravenously at $5 \mathrm{~mL} / \mathrm{s}$ flow rate followed by a saline chaser. The initiation of the scan was synchronized to the arrival of contrast in the coronary arteries by a bolus-tracking technique; (2) for the dual source CT scanner $32 \times 2 \times$ $0.6 \mathrm{~mm}$ collimation with z-flying focal spot for both detectors, gantry rotation time $330 \mathrm{~ms}$, tube voltage $120 \mathrm{kV}$ and tube current of $320-412 \mathrm{mAs}$ per rotation. A bolus of iodinated contrast material $(370 \mathrm{mgI} / \mathrm{mL}$, Ultravist; Schering, Berlin, Germany), which varied between 60 and $100 \mathrm{~mL}$, depending on the expected scan time, was injected intravenously (flow rate $5.5 \mathrm{~mL} / \mathrm{s}$ ) followed by a $40 \mathrm{~mL}$ saline chaser at the same injection rate. A bolus tracking technique was used to synchronize the arrival of contrast in the coronary arteries and the start of the acquisition. The mean effective radiation dose was $14.0 \pm 0.8 \mathrm{mSv}$ for the baseline and $10.4 \pm 3.0 \mathrm{mSv}$ for the follow-up scan, using the dose-length product and a conversion factor $\mathrm{k}(0.014 \mathrm{mSv} / \mathrm{mGy} / \mathrm{cm})$ [13]. For all datasets, axial images were reconstructed using retrospective ECG-gating, with a slice thickness of $0.75-\mathrm{mm}$, slice increment of $0.4-\mathrm{mm}$ and a medium-to-smooth convolution kernel (filtered back projection method). Optimal datasets with the best image quality were reconstructed mainly in the mid- to end-diastolic phase.

\section{CTCA image analysis}

All datasets (baseline and follow-up) were transferred to an offline workstation for analysis using semi-automated plaque analysis software (QAngioCT Research Edition v1.3.61, Medis Medical Imaging Systems, Leiden, The Netherlands) [14]. An experienced observer (3 years CTCA experience) blinded to the sequence of imaging analyzed all the scans of the main study cohort; the complete results of this temporal analysis have been previously published [11]. To examine inter-observer variability of plaque analysis a second observer (1 year CTCA experience) performed blindly the analysis on 21 segments from 10 randomly selected patients at the follow-up time point, starting completely from the raw datasets; to examine the intra-observer variability, the first reader re-analyzed all the segments in a similar blinded fashion 3 months after his/her original analysis. 
The major vessels (LAD, LCX, RCA) were considered for analysis using the modified 17-segment American Heart Association model for coronary segment classification [15]. The segments were carefully matched for all the comparisons using the bifurcations carina as landmarks. The segments of poor quality due to stack or movement artifacts, or severe calcification (with blooming artifacts preventing reliable assessment of the lumen) were excluded from analysis.

Definition of the inner lumen and outer vessel areas was performed semi-automatically following a stepwise approach. First, a centerline originating from the ostium was automatically extracted after an ostial proximal point and a distal point were placed by the observer; then straightened multi-planar reformatted images were generated and the lumen and vessel borders were detected longitudinally in 4 different longitudinal cutplanes by the software and then corrected by the observer. Based on these updated longitudinal contours, cross-sectional images at $0.5 \mathrm{~mm}$ intervals were calculated in order to create transversal lumen and vessel wall contours, which were examined and, if necessary, adjusted by the observer (Fig. 1). Gradient magnitude images, which are derived from the CTCA images and display the degree of CT density change, were used to verify the lumen and vessel wall borders.

The following quantitative parameters were derived per cross-section: the lumen area, the lumen diameter, the vessel area and the plaque burden [(plaque area/vessel area) * 100]. The plaque area was calculated by subtracting lumen area from vessel area. Geometrical parameters determined on a segmental level included the following: the mean lumen area, the mean vessel area, the mean plaque area, the plaque burden, the minimal lumen diameter (MLD) and the minimal lumen area (MLA). The mean areas were the averaged measurements of all cross-sections for each segment. Furthermore, the plaque composition was evaluated in each cross-section and in each coronary segment based on attenuation values in HU (Hounsfield Units); the mean HU and the $\%$ of voxels with attenuation values $<30 \mathrm{HU}$ (representing low attenuation plaque$\%$ LAP) were calculated for each cross-section and each coronary segment.

Observer variability and detected plaque changes over time

In order to investigate whether the observer variability using semi-automated analysis software is acceptable for monitoring the longitudinal plaque changes over time, we compared the absolute plaque change with the absolute observer variability for each segment. In this way by comparing the absolute differences, we can investigate whether the magnitude of observer variability is smaller than the magnitude of the plaque changes, while the direction of the change (positive/negative) is irrelevant to the comparison.

Statistical analysis

Continuous variables are presented as mean \pm SD or median (interquartile range-IQR) if not normally distributed. Discrete variables are presented as counts and/or percentages. The analyses were performed on both crosssectional and segmental level. The inter-observer and intraobserver agreement were assessed using the Lin's concordance correlation coefficient [CCC with the $95 \%$ confidence interval (CI)] [16]; Bland-Altman analysis [17] was performed by plotting the mean against the difference in measurements. Limits of agreement were determined by adding 1.96 standard deviations to the mean difference for the upper limit and by subtracting 1.96 standard deviations from the mean difference for the lower limit. The paired $t$ test was used to compare the absolute plaque change with the absolute observer variability. A two-sided $p$ value of less than 0.05 was used to indicate statistical significance. Statistical analyses were performed with SPSS 17.0 software (SPSS, Chicago IL).

\section{Results}

The baseline characteristics of the included patients $(\mathrm{n}=10)$ are as follows: mean age was $56 \pm 4$ and $80 \%$ were male. Regarding cardiac risk factors, 40, 10, and $50 \%$ had hypertension, diabetes mellitus, and hyperlipidemia, respectively. The untreated vessels were examined $(\mathrm{n}=19)$ and the ones with low image quality (due to motion or stack artifacts or extremely calcified coronary arteries) were excluded $(\mathrm{n}=8)$. The analyzed vessels were the left anterior descending $(\mathrm{n}=4,36 \%)$, the left circumflex $(\mathrm{n}=4,36 \%)$ and the right coronary artery $(\mathrm{n}=3,27 \%)$.

Inter-observer agreement

For the assessment of the inter-observer agreement, 945 matched cross-sections from 21 paired coronary segments were analyzed separately by 2 independent observers.

At the cross-sectional level, the mean differences for geometrical parameters were small (Table 1a), with narrow limits of agreement between observers (limits of agreement for lumen, vessel, plaque and plaque burden measurements of $2.39,-2.03 \mathrm{~mm}^{2} ; 2.81,-2.99 \mathrm{~mm}^{2} ; 2.86,-3.41 \mathrm{~mm}^{2}$; and $9.44,-11.10 \%$, respectively). The Bland-Altman analysis is shown in Fig. 2. The concordance correlation coefficients were high (Table 2a), except for the maximal plaque thickness (CCC: 0.65). For the compositional 

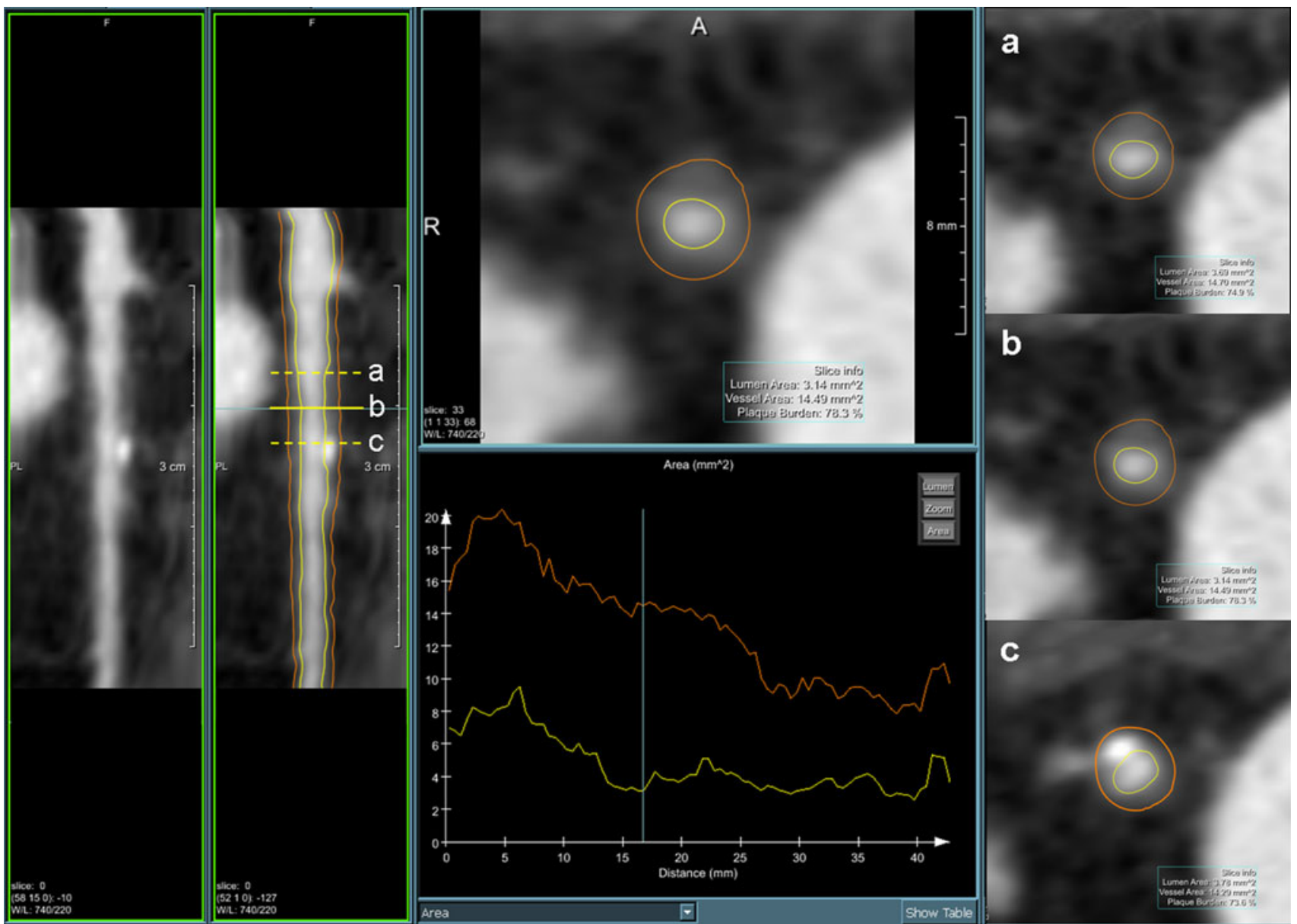

Fig. 1 Example of quantitative analysis of a left anterior descending artery. The analyzed cross-sections at 3 different levels are also shown (panels $a-c$ )

analysis as expressed by the plaque attenuation values (Table 3a), the median (IQR) difference of the attenuation between observers was $6(-4,22) \mathrm{HU}$, which corresponds to a median of $5 \%$ variability. The median (IQR) difference of the \%LAP was $-1.6(-6.3,2.1)$, which corresponds to a median of $16 \%$ inter-observer variability.

At the segmental level, the mean differences for geometrical parameters were also small (Table 1b), with narrow limits of agreement between observers (limits of agreement for lumen, vessel, plaque and plaque burden measurements of $1.12,-0.76 \mathrm{~mm}^{2} ; 1.10,-1.26 \mathrm{~mm}^{2}$; $0.94,-1.46 \mathrm{~mm}^{2}$; and $3.64 \%,-5.50 \%$ respectively). The concordance correlation coefficients were high (Table $2 b$ ). For the compositional analysis as expressed by the plaque attenuation values (Table 3a), the median (IQR) difference of the attenuation between observers was $4(-9,9) \mathrm{HU}$, which corresponds to a median of $4 \%$ variability. The median (IQR) difference of the \%LAP was $-1.7(-3.9$, 1.2 ), which corresponds to a median of $12 \%$ inter-observer variability.
Intra-observer agreement

For the assessment of the intra-observer agreement, 945 matched cross-sections from 21 paired coronary segments were fully re-analyzed by the first observer after 3 months.

At the cross-sectional level, the mean differences for geometrical parameters were small (Table 4a), with narrow limits of agreement between the two rounds of analysis (limits of agreement for lumen, vessel, plaque and plaque burden measurements of $1.62,-1.77 \mathrm{~mm}^{2} ; 2.33$, $-2.54 \mathrm{~mm}^{2} ; 2.59,-2.66 \mathrm{~mm}^{2} ;$ and $7.49 \%,-7.15 \%$ respectively). The Bland-Altman analysis is shown in Fig. 3. The concordance correlation coefficients were high (Table 5a). For the compositional analysis as expressed by the plaque attenuation values (Table 3b), the median (IQR) difference of the attenuation between the two rounds of analysis was $2(-5,11) \mathrm{HU}$, which corresponds to a median of $2 \%$ variability. The median (IQR) difference of the $\%$ LAP was $-0.7(-3.9,2.2)$, which corresponds to a median of $6 \%$ intra-observer variability. 
Table 1 Inter-observer variability of geometrical measurements
CSA cross-sectional area, $S D$ standard deviation

\begin{tabular}{|c|c|c|c|}
\hline Parameters & Observer 1 & Observer 2 & $\begin{array}{l}\text { Mean absolute } \\
\text { difference } \pm \text { SD }\end{array}$ \\
\hline
\end{tabular}

(a). Matched cross-sections $(n=945)$

$\begin{array}{lcccc}\text { Lumen CSA }\left(\mathrm{mm}^{2}\right) & 9.08 \pm 4.27 & 9.26 \pm 4.44 & 0.18 \pm 1.13 & 1.2 \\ \text { Lumen diameter }(\mathrm{mm}) & 3.31 \pm 0.77 & 3.34 \pm 0.80 & 0.03 \pm 0.19 & 0.6 \\ \text { Vessel CSA }\left(\mathrm{mm}^{2}\right) & 19.96 \pm 5.65 & 19.87 \pm 5.71 & 0.09 \pm 1.48 & 0.6 \\ \text { Plaque CSA }\left(\mathrm{mm}^{2}\right) & 10.88 \pm 2.84 & 10.61 \pm 2.61 & 0.27 \pm 1.60 & 2.2 \\ \text { Plaque burden }(\%) & 56.07 \pm 10.54 & 55.24 \pm 10.83 & 0.83 \pm 5.24 & 1.6 \\ \text { Plaque max. thickness }(\mathrm{mm}) & 1.15 \pm 0.36 & 1.10 \pm 0.39 & 0.05 \pm 0.26 & 5.5 \\ \text { (b). Matched segments }(n=21) & & & & \\ \text { Average lumen CSA }\left(\mathrm{mm}^{2}\right) & 8.92 \pm 3.90 & 9.09 \pm 4.10 & 0.18 \pm 0.48 & 1.3 \\ \text { Average vessel CSA }\left(\mathrm{mm}^{2}\right) & 19.64 \pm 5.54 & 19.56 \pm 5.62 & 0.08 \pm 0.60 & 0.6 \\ \text { Average plaque CSA }\left(\mathrm{mm}^{2}\right) & 10.73 \pm 2.29 & 10.47 \pm 2.20 & 0.26 \pm 0.61 & 2.4 \\ \text { Plaque burden }(\%) & 56.15 \pm 7.97 & 55.22 \pm 8.61 & 0.93 \pm 2.33 & 1.9 \\ \text { Minimum lumen area }\left(\mathrm{mm}^{2}\right) & 6.12 \pm 2.80 & 6.33 \pm 3.18 & 0.21 \pm 0.62 & 1.4 \\ \text { Minimum lumen diameter }(\mathrm{mm}) & 2.72 \pm 0.64 & 2.76 \pm 0.71 & 0.03 \pm 0.12 & 0.7\end{array}$
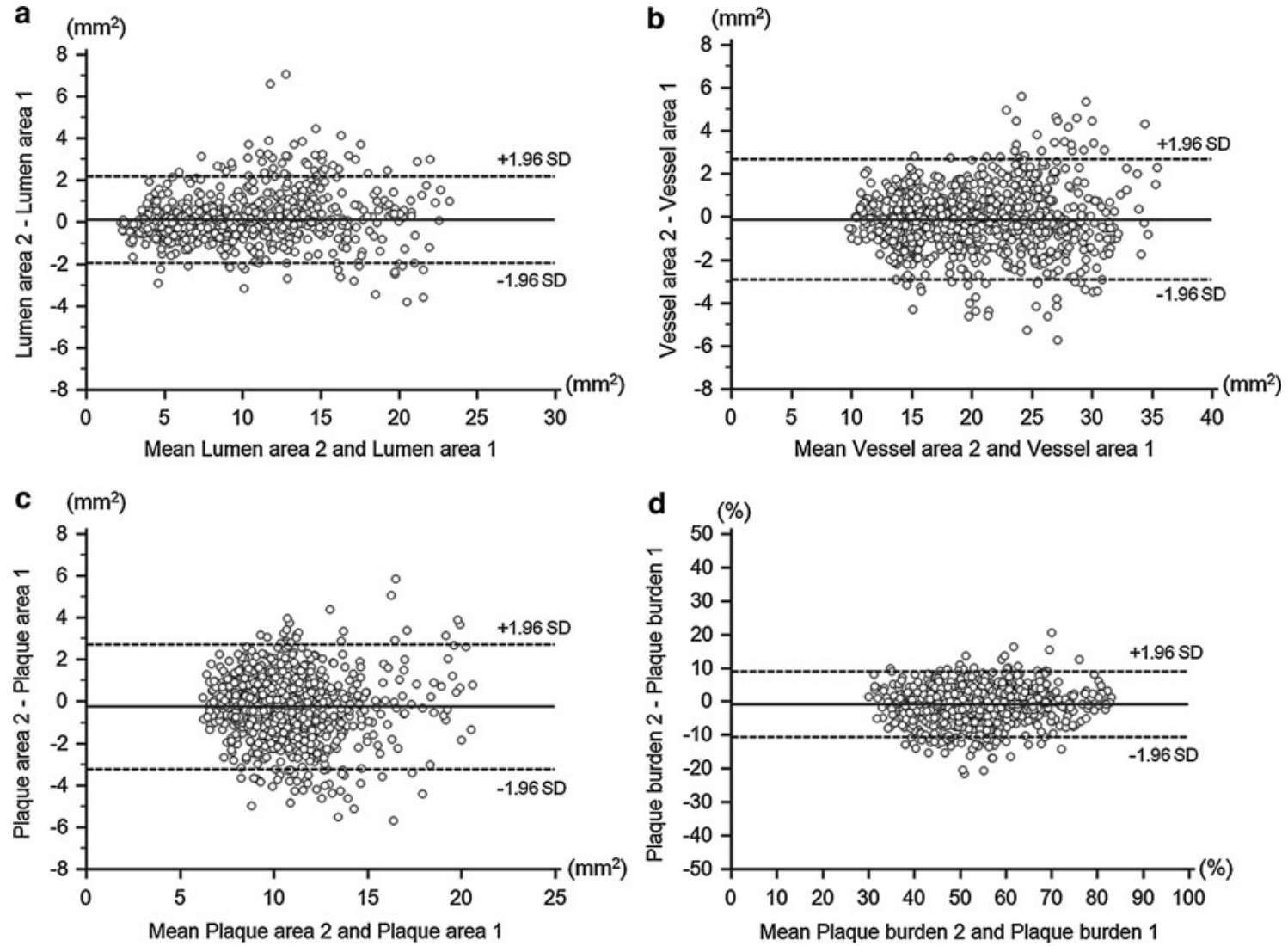

Fig. 2 Bland-Altman plots of inter-observer comparisons for lumen, vessel, plaque area and plaque burden

At the segmental level, the mean differences for geometrical parameters were small (Table 4b), with narrow limits of agreement between the two rounds of analysis (limits of agreement for lumen, vessel, plaque and plaque burden measurements of $0.83,-0.91 \mathrm{~mm}^{2} ; 0.67$, $-0.81 \mathrm{~mm}^{2} ; 0.83,-0.89 \mathrm{~mm}^{2}$; and $3.55 \%,-3.15 \%$ respectively). The concordance correlation coefficients were very high (Table 5b). For the compositional analysis as expressed by the plaque attenuation values (Table $3 b$ ), the median (IQR) difference of the attenuation between the two rounds of analysis was $1(-1,5) \mathrm{HU}$, which corresponds to a median of $<1 \%$ variability. The median (IQR) difference of the \%LAP was $-0.6(-1.6,0.3)$, which corresponds to a median of $3 \%$ intra-observer variability. 
Table 2 Correlation between different observers for geometrical and compositional parameters

Geometrical and compositional parameters $\quad$ CCC $95 \% \mathrm{CI}$

(a) Cross-sectional basis

$\begin{array}{lll}\text { Lumen area }\left(\mathrm{mm}^{2}\right) & 0.97 & 0.966-0.974 \\ \text { Lumen diameter }(\mathrm{mm}) & 0.97 & 0.969-0.976 \\ \text { Vessel area }\left(\mathrm{mm}^{2}\right) & 0.97 & 0.964-0.972 \\ \text { Plaque area }\left(\mathrm{mm}^{2}\right) & 0.83 & 0.810-0.849 \\ \text { Plaque burden }(\%) & 0.89 & 0.872-0.899 \\ \text { Maximal plaque thickness (mm) } & 0.65 & 0.615-0.688 \\ \text { Mean plaque attenuation (HU) } & 0.85 & 0.837-0.869 \\ \text { \% LAP } & 0.65 & 0.608-0.680 \\ \text { (b) Segmental basis } & & \\ \text { Mean lumen area }\left(\mathrm{mm}^{2}\right) & 0.99 & 0.988-0.998 \\ \text { Mean vessel area }\left(\mathrm{mm}^{2}\right) & 0.99 & 0.986-0.998 \\ \text { Mean plaque area }\left(\mathrm{mm}^{2}\right) & 0.96 & 0.902-0.983 \\ \text { Plaque burden }(\%) & 0.96 & 0.913-0.983 \\ \text { Minimal lumen area }\left(\mathrm{mm}^{2}\right) & 0.98 & 0.952-0.988 \\ \text { Minimal lumen diameter }(\mathrm{mm}) & 0.98 & 0.968-0.992 \\ \text { Mean plaque attenuation }(\mathrm{HU}) & 0.73 & 0.526-0.855 \\ \text { \% LAP } & 0.73 & 0.490-0.865\end{array}$

$C C C$ concordance correlation coefficient, $C I$ confidence interval, $L A P$ low attenuation plaque
Comparison of the observer variability with the plaque serial changes

For the 21 segments included in the reproducibility analysis, the absolute change (irrespectively of progression or regression) in mean plaque area between the two time points was $1.65 \pm 1.42 \mathrm{~mm}^{2}$ and the absolute change in $\%$ plaque burden was $3.55 \pm 3.02 \%$.

The absolute intra-observer variability for these parameters was significantly smaller than the serial plaque changes $\left(0.36 \pm 0.24 \mathrm{~mm}^{2}, p<0.001\right.$ for mean plaque area and $1.30 \pm 1.09 \%, p=0.001$ for plaque burden).

The absolute inter-observer variability for these parameters was also smaller than the serial plaque changes $\left(0.51 \pm 0.41 \mathrm{~mm}^{2}, p<0.001\right.$ for mean plaque area and $1.99 \pm 1.49 \%, p=0.044$ for plaque burden).

\section{Discussion}

The purpose of this study was to assess in detail the interand intra-observer reproducibility of plaque geometrical and compositional parameters using dedicated semiautomated CT plaque analysis software in vessels with mild-tomoderate atherosclerosis. To our knowledge this is the first

Table 3 Reproducibility of compositional measurements

\begin{tabular}{|c|c|c|c|c|c|}
\hline & Observer 1 & Observer 2 & $\begin{array}{l}\text { Mean absolute } \\
\text { difference } \pm \text { SD }\end{array}$ & $\begin{array}{l}\text { Median absolute } \\
\text { difference (IQR) }\end{array}$ & $\begin{array}{l}\text { Median relative } \\
\text { difference }(\%)\end{array}$ \\
\hline \multicolumn{6}{|c|}{ (a). Between different observers } \\
\hline \multicolumn{6}{|l|}{ Cross-sections $(\mathrm{n}=945)$} \\
\hline Average attenuation (HU) & $124 \pm 45$ & $135 \pm 52$ & $11 \pm 25$ & $6(-4,22)$ & 5.1 \\
\hline LAP $(\%)$ & $12.7 \pm 8.2$ & $10.5 \pm 8.7$ & $2.2 \pm 6.9$ & $-1.6(-6.3,2.1)$ & 16.4 \\
\hline \multicolumn{6}{|l|}{ Segments $(\mathrm{n}=21)$} \\
\hline Average attenuation (HU) & $125 \pm 26$ & $136 \pm 39$ & $12 \pm 22$ & $4(-9,9)$ & 4.3 \\
\hline \multirow[t]{2}{*}{ LAP $(\%)$} & $13.1 \pm 5.6$ & $10.6 \pm 7.3$ & $2.6 \pm 4.2$ & $-1.7(-3.9,1.2)$ & 12.4 \\
\hline & $\begin{array}{l}\text { Observer } 1 \\
\text { (1st time) }\end{array}$ & $\begin{array}{l}\text { Observer } 1 \\
\text { (2nd time) }\end{array}$ & $\begin{array}{l}\text { Mean absolute } \\
\text { difference } \pm \text { SD }\end{array}$ & $\begin{array}{l}\text { Median absolute } \\
\text { difference (IQR) }\end{array}$ & $\begin{array}{l}\text { Median relative } \\
\text { difference }(\%)\end{array}$ \\
\hline \multicolumn{6}{|c|}{ (b). Between the 2 rounds of the same observer } \\
\hline \multicolumn{6}{|l|}{ Cross-sections $(\mathrm{n}=945)$} \\
\hline Average attenuation (HU) & $124 \pm 45$ & $126 \pm 46$ & $4 \pm 22$ & $2(-5,11)$ & 1.6 \\
\hline LAP $(\%)$ & $12.7 \pm 8.2$ & $12.1 \pm 8.1$ & $-1.0 \pm 5.4$ & $-0.7(-3.9,2.2)$ & 6.1 \\
\hline \multicolumn{6}{|l|}{ Segments $(\mathrm{n}=21)$} \\
\hline Average attenuation (HU) & $125 \pm 26$ & $127 \pm 27$ & $2 \pm 5$ & $1(-1,5)$ & 0.5 \\
\hline LAP $(\%)$ & $13.1 \pm 5.5$ & $12.4 \pm 5.6$ & $-0.7 \pm 1.4$ & $-0.6(-1.6,0.3)$ & 2.5 \\
\hline
\end{tabular}

$I Q R$ interquartile range, $L A P$ low attenuation plaque, $S D$ standard deviation 
Table 4 Intra-observer variability of geometrical measurements
CSA cross-sectional area, $S D$ standard deviation

\begin{tabular}{lcccl}
\hline Parameters & $\begin{array}{l}\text { Observer 1 } \\
(1 \mathrm{st} \text { time })\end{array}$ & $\begin{array}{l}\text { Observer 1 } \\
(2 \mathrm{nd} \text { time })\end{array}$ & $\begin{array}{l}\text { Mean absolute } \\
\text { difference } \pm \text { SD }\end{array}$ & $\begin{array}{l}\text { Mean relative } \\
\text { difference }(\%)\end{array}$ \\
\hline (a). Matched cross-sections $(n=945)$ & & & \\
Lumen CSA $\left(\mathrm{mm}^{2}\right)$ & $9.08 \pm 4.27$ & $9.00 \pm 4.19$ & $0.08 \pm 0.87$ & 1.0 \\
Lumen diameter $(\mathrm{mm})$ & $3.31 \pm 0.77$ & $3.30 \pm 0.77$ & $0.01 \pm 0.15$ & 0.5 \\
Vessel CSA $\left(\mathrm{mm}^{2}\right)$ & $19.96 \pm 5.65$ & $19.85 \pm 5.49$ & $0.11 \pm 1.24$ & 0.4 \\
Plaque CSA $\left(\mathrm{mm}^{2}\right)$ & $10.88 \pm 2.84$ & $10.85 \pm 2.53$ & $0.03 \pm 1.34$ & 0.2 \\
Plaque burden $(\%)$ & $56.07 \pm 10.54$ & $56.23 \pm 10.33$ & $0.17 \pm 3.74$ & 0.4 \\
Plaque max. thickness $(\mathrm{mm})$ & $1.15 \pm 0.36$ & $1.16 \pm 0.37$ & $0.01 \pm 0.24$ & 0.7 \\
(b). Matched segments $(n=21)$ & & & & \\
Average lumen CSA $\left(\mathrm{mm}^{2}\right)$ & $8.92 \pm 3.90$ & $8.87 \pm 3.85$ & $0.04 \pm 0.44$ & 0.8 \\
Average vessel CSA $\left(\mathrm{mm}^{2}\right)$ & $19.64 \pm 5.54$ & $19.57 \pm 5.44$ & $0.07 \pm 0.38$ & 0.3 \\
Average plaque CSA $\left(\mathrm{mm}^{2}\right)$ & $10.73 \pm 2.29$ & $10.70 \pm 2.12$ & $0.03 \pm 0.44$ & 0.1 \\
Plaque burden $(\%)$ & $56.15 \pm 7.97$ & $56.35 \pm 8.16$ & $0.20 \pm 1.71$ & 0.4 \\
Minimum lumen area $\left(\mathrm{mm}^{2}\right)$ & $6.12 \pm 2.80$ & $5.93 \pm 2.82$ & $0.20 \pm 0.69$ & 4.1 \\
Minimum lumen diameter $(\mathrm{mm})$ & $2.72 \pm 0.64$ & $2.63 \pm 0.67$ & $0.09 \pm 0.24$ & 3.7 \\
\hline
\end{tabular}

study in which the observer variability is compared with actual serial changes in atherosclerotic plaque size. The main findings of the present study were as follows: (1) the CTCA geometrical measurements were highly reproducible in both intra- and inter-observer comparisons; (2) the compositional measurements were indeed more variable than geometrical measurements, and mostly influenced by the inter-observer variability; and (3) the intra- and interobserver variability were lower than the detected changes in plaque burden and plaque area after 3 years.

Over the recent few years, CTCA has been more commonly used as a tool to non-invasively assess the temporal
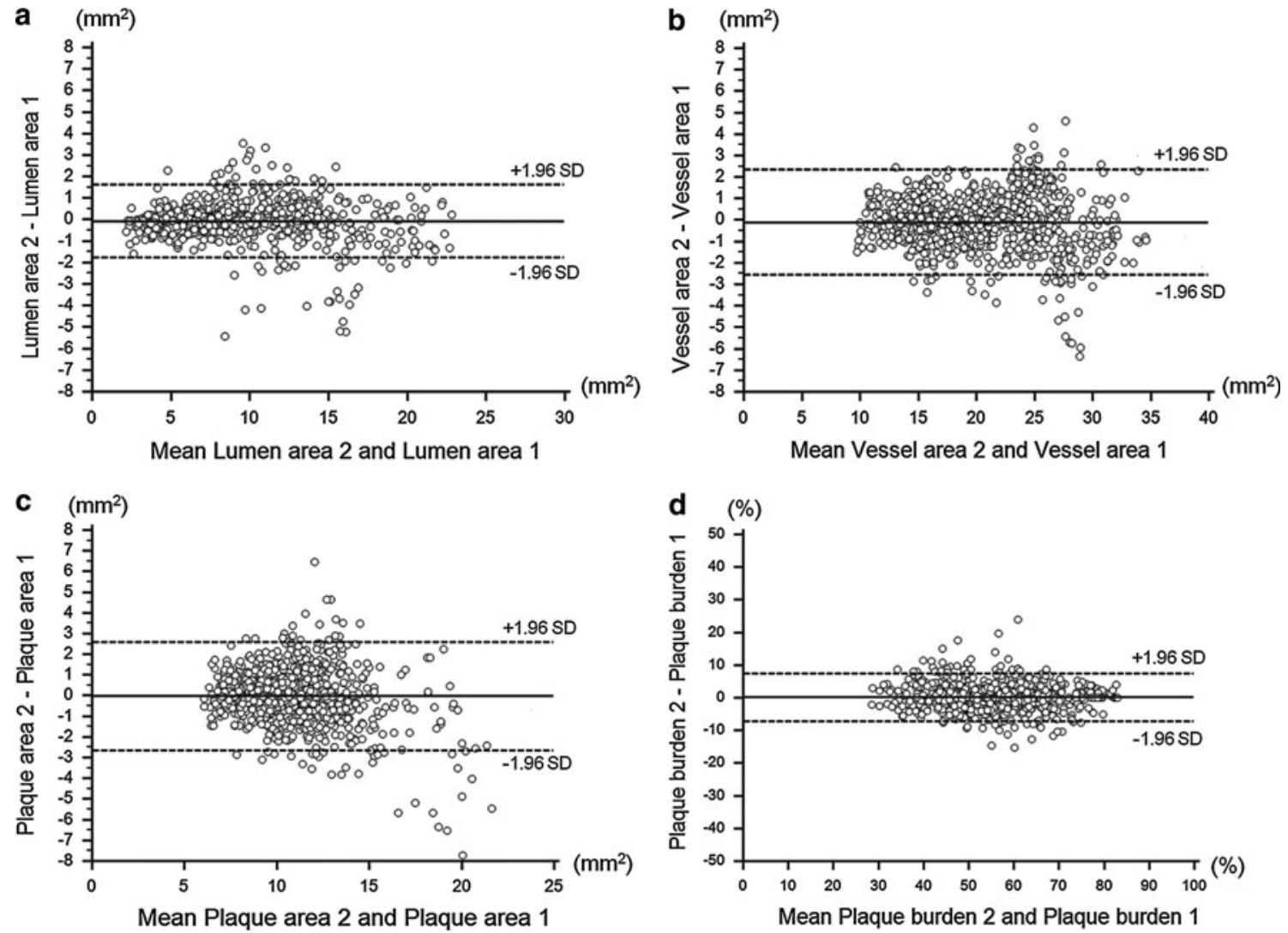

Fig. 3 Bland-Altman plots of intra-observer comparisons for lumen, vessel, plaque area and plaque burden 
Table 5 Correlation between the 2 rounds of the same observer for geometrical and compositional parameters

\begin{tabular}{lll}
\hline Geometrical and compositional parameters & CCC & 95 \% CI \\
\hline (a). Cross-sectional basis & & \\
Lumen area $\left(\mathrm{mm}^{2}\right)$ & 0.98 & $0.976-0.981$ \\
Lumen diameter (mm) & 0.98 & $0.978-0.983$ \\
Vessel area $\left(\mathrm{mm}^{2}\right)$ & 0.98 & $0.972-0.980$ \\
Plaque area $\left(\mathrm{mm}^{2}\right)$ & 0.88 & $0.860-0.889$ \\
Plaque burden $(\%)$ & 0.94 & $0.927-0.943$ \\
Maximal plaque thickness (mm) & 0.79 & $0.762-0.810$ \\
Mean plaque attenuation (HU) & 0.95 & $0.938-0.952$ \\
\% LAP & 0.82 & $0.798-0.840$ \\
(b). Segmental basis & & \\
Mean lumen area (mm $\left.{ }^{2}\right)$ & 0.99 & $0.984-0.997$ \\
Mean vessel area $\left(\mathrm{mm}^{2}\right)$ & 0.99 & $0.994-0.999$ \\
Mean plaque area $\left(\mathrm{mm}^{2}\right)$ & 0.98 & $0.956-0.991$ \\
Plaque burden $(\%)$ & 0.98 & $0.945-0.991$ \\
Minimal lumen area $\left(\mathrm{mm}^{2}\right)$ & 0.97 & $0.923-0.987$ \\
Minimal lumen diameter (mm) & 0.93 & $0.826-0.968$ \\
Mean plaque attenuation (HU) & 0.98 & $0.945-0.990$ \\
\% LAP & 0.96 & $0.909-0.984$ \\
\hline CCC & &
\end{tabular}

$C C C$ concordance correlation coefficient, $C I$ confidence interval, $L A P$ low attenuation plaque

effect of medical therapies on coronary plaque size in longitudinal studies [4-11]. Moreover, this method has the potential to assess plaque composition and therefore to assess the effect of drug therapies on the phenotype of coronary atherosclerosis. As the impact of medical treatment on the atherosclerotic plaque size and composition over time is relatively small, highly reproducible CTCA quantitative measurements are pivotal.

\section{Geometrical measurements}

In the present study, the CTCA geometrical measurements were highly reproducible in both intra- and inter-observer comparisons. Furthermore, in comparison with IVUS studies, the CTCA reproducibility appears to be comparable or better (Table 6). This improved reproducibility could be partly attributed to the semi-automated manner of the contouring in CTCA analysis. Another important consideration is the methodology for the actual analysis, since in CTCA all frames were analyzed in a stepwise approach; first the lumen and vessel wall borders were delineated as continuous lines in the longitudinal view (L-view). These contour positions functioned as landmarks for the automated contour detection in the individual cross sections; a visual inspection was performed in every cross-section and a manual correction was applied if necessary. In contrast, in IVUS only the individual cross-sections are drawn without the first step (i.e. longitudinal drawing). An additional issue is the fact that in CTCA all frames of the analyzed vessel are taken from the same cardiac cycle phase, whereas in IVUS this varies from cross-section to cross-section. In other words, in IVUS the frames are not only scrambled images (due to the longitudinal movement of the catheter inside the vessel), but also they are taken at fixed distances (i.e. $0.5-1.0 \mathrm{~mm}$ ) irrespective of the cardiac cycle phase.

The moderate concordance correlation coefficient between observers for the maximal wall thickness can be mostly attributed to the fact that this parameter depends highly on the shape of the lumen and vessel contour; a small "bump" in one of the contours would not cause a large difference in the area measurement but could substantially influence the plaque thickness.

\section{Compositional measurements}

Regarding the plaque composition, overall the differences of the average plaque attenuation between observers were very small on the cross-sectional and segment level analyses. Despite this finding, the \%LAP $(<30 \mathrm{HU})$ showed a relatively high inter-observer variability of $12 \%$, which is of major significance since the temporal change of such component could potentially become an imaging endpoint of longitudinal studies. The LAP is probably the most clinically relevant component of coronary plaques as it has been shown to correlate closely with plaques of low echogenicity (presumably lipid rich) on IVUS [18] and to have prognostic value for the development of acute coronary syndromes [19]. On the other hand, the intra-observer variability for \%LAP was low (median $3 \%$ approximately), which underlines the fact that the position of the plaque contours can play a detrimental role in the distribution of attenuation values. Small differences in the lumen or vessel wall delineation would not dramatically influence the geometrical measurements, but they could result in much bigger differences in the compositional measurements due to partial volume, i.e. in case part of the lumen or the pericoronary fat is incorrectly included in the plaque area.

Implications for the design of longitudinal studies

In the present study, the observer variability was lower than the serial changes in plaque burden-the most common endpoint in IVUS progression/regression studies. This finding suggests that CTCA data analysis using semiautomated software can detect changes in atherosclerotic plaque size beyond the observer bias. Certainly, the best approach is that the same analyst analyzes in a blind fashion both the baseline and follow-up CTCA images, 
Table 6 Observer variability for the assessment of plaque in IVUS studies

\begin{tabular}{|c|c|c|c|c|}
\hline \multirow[t]{2}{*}{ Author } & \multicolumn{2}{|c|}{$\begin{array}{l}\text { Inter-observer } \\
\text { variability } \\
\text { (difference \%) }\end{array}$} & \multicolumn{2}{|c|}{$\begin{array}{l}\text { Intra-observer } \\
\text { variability } \\
\text { (difference \%) }\end{array}$} \\
\hline & $\begin{array}{l}\text { Plaque } \\
\text { area }\end{array}$ & $\begin{array}{l}\text { Plaque } \\
\text { burden }\end{array}$ & $\begin{array}{l}\text { Plaque } \\
\text { area }\end{array}$ & $\begin{array}{l}\text { Plaque } \\
\text { burden }\end{array}$ \\
\hline Rodriguez-Granillo [20] & 10.30 & 9.50 & - & - \\
\hline Hartmann [21] & 0.89 & 0.20 & 0.35 & 0.04 \\
\hline Heo [22] & 2.50 & 1.90 & 1.60 & 0.80 \\
\hline Present study & 2.22 & 1.63 & 0.16 & 0.40 \\
\hline
\end{tabular}

IVUS intravascular ultrasound

since the difference is much lower in the intra-observer comparison for both the cross-sectional and segment based analyses than in the inter-observer comparison; more importantly, for the compositional measurements only the intra-observer variability was below the generally acceptable threshold of $10 \%$.

It should be noted that the present study was conducted on a population with mild-to-moderately diseased arteries receiving contemporary medical therapy. This was driven by the intention to study the reproducibility of this quantitative method on patients that would be the most suitable candidates for serial assessment of atherosclerosis in the "real life"; since the severe lesions would have been treated with percutaneous coronary intervention, the efficacy of the statin therapy would be monitored mainly in the untreated, mildto-moderately diseased atherosclerotic arteries.

\section{Limitations}

The studied population was small in terms of patients included; nevertheless the geometric and compositional analysis was performed on 945 matched cross-sections. Furthermore, our analysis was restricted to good quality images, which is a prerequisite for such precise CTCA quantitative analysis. We did not control for patients' characteristics in the 3 year longitudinal study. Finally, the analyzed vessels belong to a cohort of patients with mild-tomoderately diseased arteries, thus our results may not apply to other patient populations with different extent of disease; however the patients used for this study would mostly benefit from the serial assessment of atherosclerosis.

\section{Conclusions}

Considering the small changes in atherosclerotic plaque over time, reproducibility of measurements is paramount for the validity of longitudinal studies. The present study shows that the geometrical assessment of coronary atherosclerosis by CTCA is highly reproducible within and between observers using semiautomated quantification software. The compositional measurements were more variable than geometrical measurements, especially between different observers. The absolute observer variability was lower than the absolute detected serial changes in plaque burden and plaque area after 3 years.

Conflict of interest None.

\section{References}

1. Smith SC Jr, Jackson R, Pearson TA, Fuster V, Yusuf S, Faergeman O, Wood DA, Alderman M, Horgan J, Home P, Hunn M, Grundy SM (2004) Principles for national and regional guidelines on cardiovascular disease prevention: a scientific statement from the World Heart and Stroke Forum. Circulation 109(25):3112-3121. doi:10.1161/01.CIR.0000133427.35111.67

2. de Feyter PJ, Serruys PW, Davies MJ, Richardson P, Lubsen J, Oliver MF (1991) Quantitative coronary angiography to measure progression and regression of coronary atherosclerosis. Value, limitations, and implications for clinical trials. Circulation 84(1): 412-423

3. Mintz GS, Garcia-Garcia HM, Nicholls SJ, Weissman NJ, Bruining N, Crowe T, Tardif JC, Serruys PW (2011) Clinical expert consensus document on standards for acquisition, measurement and reporting of intravascular ultrasound regression/progression studies. EuroIntervention 6(9):1123-1130, 1129. doi:10.4244/EIJV 6I9A195

4. Burgstahler C, Reimann A, Beck T, Kuettner A, Baumann D, Heuschmid M, Brodoefel H, Claussen CD, Kopp AF, Schroeder S (2007) Influence of a lipid-lowering therapy on calcified and noncalcified coronary plaques monitored by multislice detector computed tomography: results of the New Age II Pilot Study. Invest Radiol 42(3):189-195. doi:10.1097/01.rli.0000254408. 96355.85

5. Uehara M, Funabashi N, Mikami Y, Shiina Y, Nakamura K, Komuro I (2008) Quantitative effect of atorvastatin on size and content of non-calcified plaques of coronary arteries 1 year after atorvastatin treatment by multislice computed tomography. Int J Cardiol 130(2):269-275. doi:10.1016/j.ijcard.2007.07.013

6. Schmid M, Achenbach S, Ropers D, Komatsu S, Ropers U, Daniel WG, Pflederer T (2008) Assessment of changes in noncalcified atherosclerotic plaque volume in the left main and left anterior descending coronary arteries over time by 64-slice computed tomography. Am J Cardiol 101(5):579-584. doi: 10.1016/j.amjcard.2007.10.016

7. Lehman SJ, Schlett CL, Bamberg F, Lee H, Donnelly P, Shturman L, Kriegel MF, Brady TJ, Hoffmann U (2009) Assessment of coronary plaque progression in coronary computed tomography angiography using a semiquantitative score. JACC Cardiovasc Imaging 2(11):1262-1270. doi:10.1016/j.jcmg.2009.07.007

8. Hoffmann H, Frieler K, Schlattmann P, Hamm B, Dewey M (2010) Influence of statin treatment on coronary atherosclerosis visualised using multidetector computed tomography. Eur Radiol 20(12):2824-2833. doi:10.1007/s00330-010-1880-x

9. Inoue K, Motoyama S, Sarai M, Sato T, Harigaya H, Hara T, Sanda Y, Anno H, Kondo T, Wong ND, Narula J, Ozaki Y (2010) Serial coronary CT angiography-verified changes in plaque characteristics as an end point: evaluation of effect of statin intervention. JACC Cardiovasc Imaging 3(7):691-698. doi: 10.1016/j.jcmg.2010.04.011 
10. Tardif JC, L'Allier PL, Ibrahim R, Gregoire JC, Nozza A, Cossette M, Kouz S, Lavoie MA, Paquin J, Brotz TM, Taub R, Pressacco J (2010) Treatment with 5-lipoxygenase inhibitor VIA2291 (Atreleuton) in patients with recent acute coronary syndrome. Circ Cardiovasc Imaging 3(3):298-307. doi:10.1161/ CIRCIMAGING.110.937169

11. Papadopoulou SL, Neefjes LA, Garcia-Garcia HM, Flu WJ, Rossi A, Dharampal AS, Kitslaar PH, Mollet NR, Veldhof S, Nieman K, Stone GW, Serruys PW, Krestin GP, de Feyter PJ (2012) Natural history of coronary atherosclerosis by multislice computed tomography. JACC Cardiovasc Imaging 5(3 Suppl):S28-S37. doi:10.1016/j.jcmg.2012.01.009

12. Nissen SE, Nicholls SJ, Sipahi I, Libby P, Raichlen JS, Ballantyne CM, Davignon J, Erbel R, Fruchart JC, Tardif JC, Schoenhagen P, Crowe T, Cain V, Wolski K, Goormastic M, Tuzcu EM (2006) Effect of very high-intensity statin therapy on regression of coronary atherosclerosis: the ASTEROID trial. JAMA 295(13): 1556-1565. doi:10.1001/jama.295.13.jpc60002

13. Bongartz G, Golding SJ, Jurik AG, Leonardi M, van Persijn van Meerten E, Rodríguez R, Schneider K, Calzado A, Geleijns J, Jessen KA, Panzer W, Shrimpton PC, Tosi G (2004) CT quality criteria-appendix C. European Guidelines for Multislice Computed Tomography, European Commission. Available at: http:// www.msct.eu/CT_Quality_Criteria.htm

14. Boogers MJ, Broersen A, van Velzen JE, de Graaf FR, El-Naggar HM, Kitslaar PH, Dijkstra J, Delgado V, Boersma E, de Roos A, Schuijf JD, Schalij MJ, Reiber JH, Bax JJ, Jukema JW (2012) Automated quantification of coronary plaque with computed tomography: comparison with intravascular ultrasound using a dedicated registration algorithm for fusion-based quantification. Eur Heart J 33(8):1007-1016. doi:10.1093/eurheartj/ehr465

15. Austen WG, Edwards JE, Frye RL, Gensini GG, Gott VL, Griffith LS, McGoon DC, Murphy ML, Roe BB (1975) A reporting system on patients evaluated for coronary artery disease. Report of the Ad Hoc Committee for Grading of Coronary Artery
Disease, Council on Cardiovascular Surgery, American Heart Association. Circulation 51(4 Suppl):5-40

16. Lin LI (1989) A concordance correlation coefficient to evaluate reproducibility. Biometrics 45(1):255-268

17. Bland JM, Altman DG (1986) Statistical methods for assessing agreement between two methods of clinical measurement. Lancet 1(8476):307-310

18. Motoyama S, Kondo T, Anno H, Sugiura A, Ito Y, Mori K, Ishii J, Sato T, Inoue K, Sarai M, Hishida H, Narula J (2007) Atherosclerotic plaque characterization by $0.5-\mathrm{mm}$-slice multislice computed tomographic imaging. Circ J 71(3):363-366

19. Motoyama $S$, Sarai $M$, Harigaya $H$, Anno $H$, Inoue $K$, Hara $T$, Naruse H, Ishii J, Hishida H, Wong ND, Virmani R, Kondo T, Ozaki Y, Narula J (2009) Computed tomographic angiography characteristics of atherosclerotic plaques subsequently resulting in acute coronary syndrome. J Am Coll Cardiol 54(1):49-57. doi: 10.1016/j.jacc.2009.02.068

20. Rodriguez-Granillo GA, Vaina S, Garcia-Garcia HM, Valgimigli M, Duckers E, van Geuns RJ, Regar E, van der Giessen WJ, Bressers M, Goedhart D, Morel MA, de Feyter PJ, Serruys PW (2006) Reproducibility of intravascular ultrasound radiofrequency data analysis: implications for the design of longitudinal studies. Int J Cardiovasc Imaging 22(5):621-631. doi:10.1007/s10554006-9080-0

21. Hartmann M, Mattern ES, Huisman J, van Houwelingen GK, de Man FH, Stoel MG, Danse PW, Louwerenburg HW, von Birgelen C (2009) Reproducibility of volumetric intravascular ultrasound radiofrequency-based analysis of coronary plaque composition in vivo. Int J Cardiovasc Imaging 25(1):13-23. doi:10.1007/s10554008-9338-9

22. Heo JH, Brugaletta S, Garcia-Garcia HM, Gomez-Lara J, Ligthart JM, Witberg K, Magro M, Shin ES, Serruys PW (2011) Reproducibility of intravascular ultrasound iMAP for radiofrequency data analysis: implications for design of longitudinal studies. Catheter Cardiovasc Interv. doi:10.1002/ccd.23335 